DESENVOLVMENTO
$\begin{aligned} & \text { SISTEMA } \\ & \text { E MEIO AMBIENTE }\end{aligned}$

\title{
Produção audiovisual na formação de professores- pesquisadores: olhares compartilhados sobre o Parque Nacional da Restinga de Jurubatiba
}

\section{Audiovisual production in teacher-researcher education: shared views on the Restinga National Park of Jurubatiba}

\author{
Rafael Nogueira COSTA ${ }^{1 *}$, Fátima Teresa Braga BRANQUINHO², Celso Sánchez PEREIRA ${ }^{3}$ \\ ${ }^{1}$ Programa de Pós-Graduação em Ciências Ambientais e Conservação (PPG-CiAC), Universidade Federal do Rio de Janeiro (UFRJ), Macaé, \\ RJ, Brasil. \\ ${ }^{2}$ Universidade do Estado do Rio de Janeiro (UERJ), Rio de Janeiro, RJ, Brasil. \\ ${ }^{3}$ Universidade Federal do Estado do Rio de Janeiro (UNIRIO), Rio de Janeiro, RJ, Brasil. \\ *E-mail de contato: rafaelnogueiracosta@gmail.com
}

Artigo recebido em 29 de junho de 2017, versão final aceita em 8 de março de 2018.

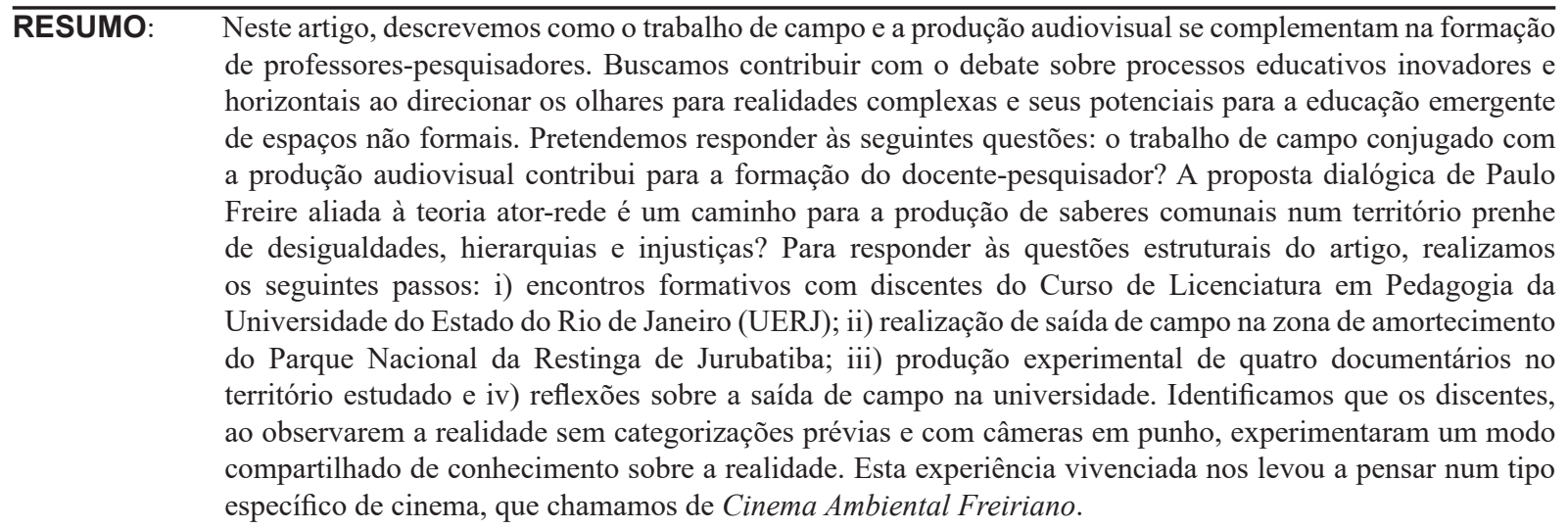

Palavras-chave: cinema ambiental freiriano; educação ambiental; teoria ator-rede; Bruno Latour; Paulo Freire. 
ABSTRACT: We seek to contribute to the debate on innovative and horizontal educational processes by targeting complex realities and their potential for the emerging education of non-formal areas. We intend to answer the following questions: Does field work combined with audiovisual production contribute to teacher-researcher education? Is Paulo Freire's dialogical proposal allied to the actor-network theory a way to the production of collective knowledge in a territory full of inequalities, hierarchies and injustices? In order to answer the structural questions of the article, we performed the following steps: i) formative meetings with students of the Pedagogy Graduation Course of the Rio de Janeiro State University (UERJ); ii) completion of field research in the buffer zone of the Restinga de Jurubatiba National Park; iii) experimental production of four documentaries in the studied territory; and iv) reflections on the field research in the university. We have identified that students, by observing reality without predetermined categories and with the camera in hands, have experienced a specific kind of production of knowledge about reality. This experience has led us to think about a specific kind of cinema, which we call Freirean Environmental Cinema ("Cinema Ambiental Freiriano").

Keywords: Freirean environmental cinema; environmental education; actor-network theory; Bruno Latour; Paulo Freire.

\section{Introdução}

Este artigo tem como objetivo refletir sobre a formação docente a partir de uma experiência de campo aliada à produção audiovisual ${ }^{1}$. Articulamos elementos teóricos dos estudos de Bruno Latour com os marcos referenciais da pedagogia freiriana. Reconhecemos as limitações das implicações teóricas e metodológicas com ambos autores, que possuem diferentes abordagens epistemológicas. Os recortes possíveis foram pensados visando a discussão de uma estratégia pedagógica, dialógica e horizontal.

Almeida (2017) sintetiza as múltiplas possibilidades entre cinema e educação, destacando o uso do cinema como ferramenta didática e espaço para criação e produção de sentidos. Essas relações nos colocam diante de novas teorias e práticas pedagógicas que ainda não foram totalmente compreendidas (Goldfarb, 2002) por serem novas formas de descobrir e compartilhar conhecimento (Migliorin \& Barroso, 2016).

Estes foram os elementos motivadores para experimentar em conjunto com os estudantes do curso de Licenciatura em Pedagogia da Universidade do Estado do Rio de Janeiro (UERJ) momentos para a produção de sentidos num território recheado de controvérsias.

O pensamento de Paulo Freire nos conduziu porque seus escritos a favor da autonomia dos educandos (Freire, 1996) giram em torno das nossas reflexões. Esta proposta é contrária ao ensino tradicional, que é em sua essência verticalizado, fechado em sala de aula e calcado em realidades únicas e, quase sempre, inquestionáveis.

Desta forma, pautamo-nos nos princípios da Lei de Diretrizes e Bases da Educação Nacional que, em seu artigo $3^{\circ}$, busca "a valorização da experiência extraescolar" (Brasil, 1996). Tal ponto de vista nos aproxima, portanto, das questões levantadas no

${ }^{1} \mathrm{O}$ estudo de caso descrito neste artigo foi parte fundante da atividade de estágio-docência durante o doutoramento do primeiro autor. 
trabalho de campo realizado na fronteira ${ }^{2}$ do Parque Nacional da Restinga de Jurubatiba.

Este artigo pretende responder às seguintes questões: o trabalho de campo conjugado com a produção audiovisual contribui para a formação do docente-pesquisador? A proposta dialógica de Paulo Freire aliada à teoria ator-rede é um caminho para a produção de saberes comunais num território ${ }^{3}$ prenhe de desigualdades, hierarquias e injustiças?

O artigo está dividido em três seções, além desta introdução. Na primeira seção, são apresentados os procedimentos docentes, explicitando-se o referencial teórico-metodológico relacionado à produção audiovisual adotado no trabalho de campo. Na segunda seção, a conservação da natureza, a possibilidade de remoção das residências e a expansão da atividade petrolífera, atividade geradora de impactos ambientais (Brasil, 1981) são os assuntos registrados pelos equipamentos dos estudantes e, portanto, compõem o coletivo ${ }^{4} \mathrm{em}$ acordo com a teoria ator-rede (Latour, 2012). Na terceira seção, apresentamos os resultados e as discussões sobre a importância do trabalho de campo para a formação de docentes-pesquisadores com base na perspectiva do que propomos como Cinema Ambiental Freiriano.

\section{Saída de campo e narrativa audiovisual na formação de professores-pesquisadores}

As reflexões realizadas pelos discentes da Licenciatura em Pedagogia da UERJ, após saída de campo, nos conduziram à construção deste artigo. Entretanto, a experiência em produzir filmes com a temática socioambiental faz parte das nossas ações desde 2011, quando iniciamos uma proposta de produção audiovisual como forma de Extensão Universitária ${ }^{5}$ no Curso de Graduação em Ciências Biológicas (licenciatura e bacharelado) da Universidade Federal do Rio de Janeiro (UFRJ) em Macaé.

A proposta de criação de narrativas audiovisuais em paisagens híbridas e em diálogo com os atores que vivenciam os territórios onde "as naturezas" são moldadas por disputas políticas, nos faz pensar na possibilidade de produção de um tipo de cinema intitulado Cinema Ambiental Freiriano, inspirado na obra do educador Paulo Freire.

Sabemos que esse educador não acompanhou a revolução digital ${ }^{6}$ da virada do século $\mathrm{XX}$, a qual amplificou os modos de ver e olhar as transformações da sociedade, gerando uma proliferação de imagens captadas por diferentes equipamentos.

\footnotetext{
${ }^{2}$ Resolvemos manter a expressão fronteira, pois carrega muitos significados para este estudo. Entretanto, fronteira é um conceito que não se aplica à teoria ator-rede descrita em Latour (2012), pois nesta proposta teórica as fronteiras são pouco evidentes, desfeitas ou borradas, só existindo enquanto linguagem.

${ }^{3}$ Sugerimos aos leitores, antes de ler este artigo, experimentar a ferramenta Park View. Provavelmente, sua visita será diferente da realidade, em face de suas limitações. Implementada por um convênio entre o ICMBio e a empresa Google, o Park View tem o objetivo de "possibilitar ao cidadão fazer um tour virtual pelas reservas e parques nacionais por meio de um programa de computador" (Fonte: EBC. Disponível em: $<$ http://bit.ly/1PzzCrs>. Acesso em: 28 jan. 2018).

${ }^{4}$ Para Latour, coletivo "não nos remete a uma unidade já feita, mas a um procedimento para coligar as associações de humanos e de não humanos" (Latour, 2004, p. 373).

${ }^{5}$ Nesta proposta, intitulada Coletivo de Pesquisa em Cinema Ambiental (CUCA/UFRJ), as portas da universidade são abertas para criação de um espaço de formação em produção audiovisual com base nas discussões do campo da Educação Ambiental. As construções buscam seguir uma lógica compartilhada e nosso maior interesse é "desmanchar" as fronteiras do Parque Nacional da Restinga de Jurubatiba.

${ }^{6} \mathrm{Na}$ análise de Sodré (2012, p. 171) estamos diante de "um policulturalismo que parece disseminar ao infinito os seus produtos - novelas e séries televisivas, telefilmes, games, best-sellers, block-buster cinematográficos, redes sociais, etc."
} 
Mesmo assim, sua forma de pensar a educação nos possibilita imaginar e experimentar esse tipo de cinema, construído com atenção e interesse no diálogo.

Ao realizarmos uma ação educativa in loco, estamos propondo um diálogo horizontal que substitui "o antidiálogo, a sloganização, a verticalidade, os comunicados", que funcionam como "instrumentos da domesticação" (Freire, 2013, p. 72). É, portanto, por estes caminhos epistemológicos que nos aproximamos da obra e do pensamento de Paulo Freire, propondo uma articulação com o cinema como forma de reflexão.

Assim, a realização de filmes que retratem diferentes realidades, em que o cineasta não é unicamente aquele que escolhe, que dirige, mas também aquele que desliga a câmera e conversa com o sujeito - que, ao ser filmado, também escolhe, filma e cria em comunhão - "afirma a dialogicidade e se faz dialógica" (Freire, 2013, p. 95). Um tipo de cinema "problematizador, de caráter autenticamente reflexivo", implicando, desta forma, num movimento constante de "desvelamento da realidade", um relacionamento que se faz no contato (Freire, 2013, p. 97).

Esta "cena da pesquisa de campo" é definida por Souza (2017) como "olho da câmera", que deve buscar o registro de atos, expressões, falas, silêncios e outros sinais que surgem entre o pesquisador e seus interlocutores.

Com base nestes conceitos, o foco da lente do pesquisador-cineasta não está exclusivamente na fala do sujeito da pesquisa isoladamente, mas na cena dialógica que se estabelece entre o pesquisador e seu outro, produzindo sentidos, acordos e negociações sobre o que pensam sobre um determinado assunto, em um contexto definido por atos de falas recíprocas. Isto significa dizer que, desde o início, o enquadramento da filmagem no campo deve estar voltado para o diálogo (Souza, 2017, p. 11).

A teoria ator-rede complementa o pensamento freiriano ao revelar a continuidade e as conexões por meio da multiplicidade de atores. Para Latour, o pesquisador precisa estar atento às conexões, pois não apenas os humanos escolhem, agenciam, tecem a realidade, mas os não humanos também o fazem. Essa experiência coletiva em movimento oferece "versões múltiplas e rapidamente revistas", em que "somos todos arrastados" (Latour, 2004, p. 365).

São estas reflexões que inspiraram o trabalho realizado com vinte e três alunos do Curso de Graduação em Pedagogia da UERJ. A saída de campo foi organizada durante cinco reuniões presenciais, totalizando vinte horas, no âmbito da disciplina obrigatória Pesquisa e Prática Pedagógica. Os encontros foram conduzidos com exposição teórica, diálogos circulares com trocas de experiências, atividade prática para captação de imagem e som, centradas na discussão sobre documentários participativos e finalizando com uma saída de campo ${ }^{7}$ com duração de dois dias.

A atividade de campo envolveu palestras, projeções de fotos e vídeos, visita ao Parque Nacional da Restinga de Jurubatiba e à sua zona de amortecimento, com observações e entrevistas (que o grupo da pesquisa assume como "conversas") no bairro do Lagomar e na área da expansão do terminal de petróleo. O debate final aconteceu no Núcleo em Ecologia e Desenvolvimento Socioambiental de

${ }^{7}$ A discussão deste artigo está concentrada na etapa final deste processo, a saída de campo e as reflexões dos estudantes sobre a vivência. 
Macaé (NUPEM), nas dependências da UFRJ, onde o áudio do debate foi gravado, transcrito e analisado.

Devido à riqueza das discussões, decidimos concentrar as análises na última etapa da atividade, no qual foram compartilhados, pelos estudantes, os diferentes olhares e percepções sobre o território estudado. Na próxima seção, desdobraremos algumas controvérsias nas fronteiras entre a conservação da natureza e a expansão da atividade econômica ligada ao petróleo, ambas ameaças constantes de remoção dos moradores do Bairro Lagomar, em Macaé (RJ), território investigado pelos estudantes em formação.

\section{Controvérsias nas fronteiras entre a conservação da natureza, o petróleo e a comunidade}

De acordo com Latour (2012, p. 53), os movimentos de desdobrar controvérsias "proporcionam ao analista os recursos necessários para rastrear as conexões sociais". Desta forma, possibilitam mapear algo pertencente aos territórios. Com isso em mente, resolvemos seguir o caminho do petróleo e olhar de maneira atenta as controvérsias em relação às fronteiras da conservação da natureza e do terminal de armazenamento de óleo e gás.

De um lado temos uma vasta área de restinga legalmente "intocável", com mais de dezoito lagoas costeiras, que é protegida pelos cientistas da natureza, pelo Instituto Chico Mendes de Conservação da Biodiversidade (ICMBio) e pelas ONGs, que formam uma unidade em prol da sua conservação (Medeiros \& Pereira, 2011). Do outro lado, temos a atividade petrolífera, com seus gasodutos, terminais de armazenamento e distribuição de óleo e gás 8888 , gerador de "riqueza" e principal atividade econômica da região nordeste do Estado do Rio de Janeiro do final do século XX até a queda do preço deste hidrocarboneto no início do século XXI. Completando a paisagem, o bairro mais populoso da "Capital do Petróleo", Lagomar. A expansão da atividade de exploração petrolífera em Macaé é, sem dúvida, a principal influência em sua dinâmica de crescimento populacional e a base fundamental para seu desenvolvimento econômico (Dias, 2013).

Nestas fronteiras caminhamos, seguimos os atores, traçamos conexões e dialogamos com os moradores, os gestores ambientais e os trabalhadores da indústria do petróleo. Juntamos fragmentos de conversas, documentos técnicos, registros produzidos por jornalistas, cientistas, cineastas, educadores ambientais $^{9}$ e fotógrafos. Estamos sistematizando nossas observações em artigos científicos (Costa \& Branquinho, 2016; Fuentes et al., 2016) e filmes ${ }^{10}$. Três documentários produzidos pelo Coletivo de Pesquisa em Cinema Ambiental (CUCA/UFRJ)

\footnotetext{
${ }^{8} \mathrm{O}$ gasoduto Rota Cabiúnas “tem a capacidade de transportar 13 milhões de metros cúbicos de gás por dia, e levará o gás até o Terminal de Cabiúnas (TECAB) em Macaé/RJ”. (Relatório de Impacto Ambiental, Atividade de Produção e Escoamento de Petróleo e Gás Natural do Polo Pré-Sal da Bacia de Santos (Petrobras, 2014). Disponível em: <http://bit.ly/2g8WBeW>. Acesso em: 21 nov. 2016.)

${ }^{9}$ O filme Vento corredor (2007), elaborado por ação de educadores ambientais vinculados ao licenciamento de petróleo (Costa et al., 2016), apresentou, com base em entrevistas diretas, diferentes visões sobre este território. Neste filme, podemos identificar o choque dos discursos: de um lado, o gestor ambiental "defendendo a natureza", e do outro, os moradores, apresentando suas preocupações em relação à possibilidade de remoção das suas moradias, o que levaria, assim, suas próprias raízes. Mais de uma década após a produção deste filme, as narrativas dos moradores parecem descrever o momento atual.
}

${ }^{10}$ Os filmes podem ser acessados nos seguintes sítios: www.cuca.bio.br e http://www.macae.ufrj.br/nupem/. 
apresentam estas fronteiras em diferentes perspectivas: Um dia novinho em folha (2013), Espelho d'água: Bailarina do Lagomar (2015) e Cicatrizes numéricas (2017).

Em Macaé, o bairro Lagomar apresentou o maior crescimento populacional do município, mais de $400 \%$ entre os anos de 2000 e 2010 (Macaé, 2012), abrigando aproximadamente 50.000 moradores (Correa, 2012) e a maior concentração de migrantes da cidade (Silva \& Faria, 2012). O bairro surgiu com a aprovação de um loteamento em 1976. Na área, foram projetados 527 "sítios de recreio" com $5.000 \mathrm{~m}^{2}$ - que, posteriormente, foram "ocupados clandestinamente, descaracterizando completamente a proposta original" (Macaé, 2010 , p. 25). Por conta desta invasão, foram feitas denúncias ao Núcleo do Ministério Público Federal e ao Ministério Público Estadual no ano de 2007, visando o ordenamento urbano da área (Faria \& Tougeiro, 2010).

As condições sanitárias (contaminação do lençol freático ${ }^{11}$ ) e a proximidade do gasoduto levaram o poder municipal a classificar o bairro como "assentamento precário", em "críticas condições de urbanização e em situação de risco" (Macaé, 2012, p. 175; Correa, 2012).

Neste território, a tensão entre a gestão da área e a dificuldade de participação das populações locais vem sendo constantemente descritas na literatura acadêmica (Santos, 2008; Vainer, 2010; Madeira Filho et al., 2011; Leal, 2013) e, em alguns casos, chegou a envolver disputas jurídicas entre o Mi- nistério Público Federal e a Prefeitura de Macaé (Madeira Filho et al., 2011).

Observam-se diferentes interesses: extração e movimentação de óleo e gás (ciclo predatório e passageiro); manutenção da biodiversidade no Parque Nacional da Restinga de Jurubatiba e urbanização de uma localidade em expansão e sem infraestrutura básica. Este contraste entre as diferentes dimensões políticas foram as principais controvérsias em relação ao território discutido na atividade (Figura 1).

O terminal terrestre de Cabiúnas recebe e armazena o petróleo extraído das plataformas na Bacia de Campos para Barra do Furado, Campos Elíseos e Duque de Caxias. Os canos são facilmente visualizados "cortando" a restinga e "separando" a área protegida do bairro, marcando uma divisão de 4,2 quilômetros de extensão. Se por um lado observamos os canos que transportam a "riqueza", impulsionada pelo desenvolvimento técnico-econômico, por outro vemos a distribuição social dos riscos, no qual as pretensões de controle, com base na tecnologia, chocam-se com a deficiência de segurança (Beck, 2011).

Madeira Filho et al. (2011) detalham o imbróglio jurídico e burocrático do qual participam diferentes atores. O centro da controvérsia gira em torno do Procurador da República e do Procurador da "Capital do Petróleo". O fio condutor é a Ação Civil Pública impetrada pelo Ministério Público Federal em 2002, determinando que parte do Loteamento Lagomar próximo à $\mathrm{UC}^{12}$ fosse desapropriada, inclusive celebrando um Termo de

\footnotetext{
${ }^{11}$ A construção de uma vasta rede de poços para obtenção de água nas proximidades do lançamento de esgoto in natura pelas residências é a principal causa da contaminação da água, a qual é utilizada pela população local para diversos fins, inclusive consumo (Cuzzati et al., 2011; Cordeiro et al., 2012). Lamego (1945) já relatava o uso de água de poço para consumo na região desde os grupos indígenas, como os Goitacá.

${ }^{12}$ De acordo com o Sistema Nacional de Unidades de Conservação da Natureza (SNUC), a zona de amortecimento é "o entorno de uma unidade de conservação, onde as atividades humanas estão sujeitas a normas e restrições específicas, com o propósito de minimizar os impactos negativos sobre a unidade" (Brasil, 2000).
} 


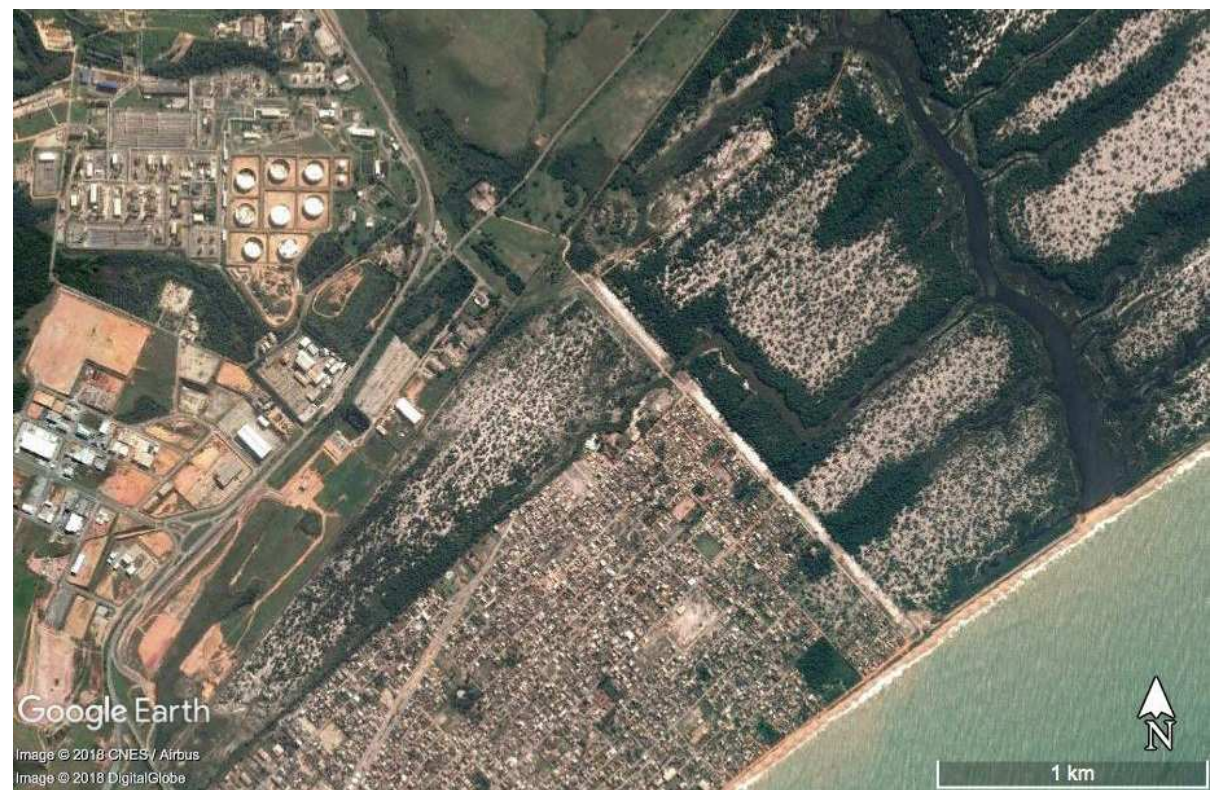

FIGURA 1 - Imagem das fronteiras. Legenda: O encontro entre o Parque Nacional da Restinga de Jurubatiba, o Bairro Lagomar e o Terminal Cabiúnas.

FONTE: Google Earth.

Ajustamento de Conduta (TAC) com a Prefeitura Municipal de Macaé (Figura 3).

A referida Ação Civil Pública foi amplamente noticiada pelos jornais locais e o Parque Nacional da Restinga de Jurubatiba vira assim um ator, passando a ser pivô da desapropriação das famílias localizadas próximas à UC. Abaixo, destacamos algumas declarações de diferentes atores veiculadas na mídia local:

"O poder público nunca impediu esses moradores de construir casas nesse local. Agora, eles querem tirar essas famílias que não vão ter onde morar" (Presidente da Associação de Moradores). (O Debate, 2011. Disponível em: http://bit.ly/2nlWx0A).

"Nós investimos muito na construção de nossas casas. Não temos dinheiro, mas temos muita disposição para trabalhar. E foi assim que construímos nossas casas. Então, não queremos impedir a desapropriação das casas. Só queremos um local para morar depois. Não precisa ser muito, basta ser digno" (moradora do Bairro Lagomar). (O Debate, 2011. Disponível em: http://bit.ly/2nlWx0A).

"As construções não pararam e saltaram de aproximadamente 150 em 2005 para cerca de 340, em 2011. Com isso o próprio Parque entende que hoje se tornou inviável a retirada de todas as famílias que ali vivem" (Analista ambiental do ICMBio). (O Debate, 2012. Disponível em: http://bit.ly/2Fq9zS4).

"Seguimos a determinação do MPF que prevê a remoção dos imóveis construídos de forma irregular na zona de amortecimento do Parque" (Secretária de Habitação). (O Debate, 2015. Disponível em: http:// bit.ly/1TjuVkQ).

"Esse é um trabalho importante, que visa garantir ao município a solução para um impasse que se arrasta há quase 10 anos" (Vereador). (O Debate, 2015. Disponível em: http://bit.ly/1TjuVkQ). 
Uma questão que aparece pouco nas falas dos atores é o risco de explosão do gasoduto, como o ocorrido em 1984 na Vila Socó, em Cubatão, São Paulo (Machado, 2006). Essas questões ainda são deixadas de lado, ou são simplesmente desconhecidas pela ciência, necessitando de novas mediações e reflexões sobre o futuro que queremos como modelo de desenvolvimento (Bosco \& Di Giulio, 2015).

Buscando demonstrar ainda que a fronteira presente na tríade "conservação, comunidade e atividade petrolífera" é muito mais fluida do que pública do Terminal Portuário para a expansão da atividade de escoamento de petróleo em Macaé, observou-se que o ICMBio manifestou-se contrariamente ao empreendimento devido à proximidade com a UC de menos de três quilômetros.

No dia 08 de setembro de 2015, a Coordenadoria Regional (CR8) do ICMBio emitiu ofício ${ }^{13}$ ao presidente do Instituto Estadual do Ambiente (INEA) indeferindo a solicitação de autorização para o licenciamento ambiental do empreendimento. Entre os argumentos contrários, constavam: i)
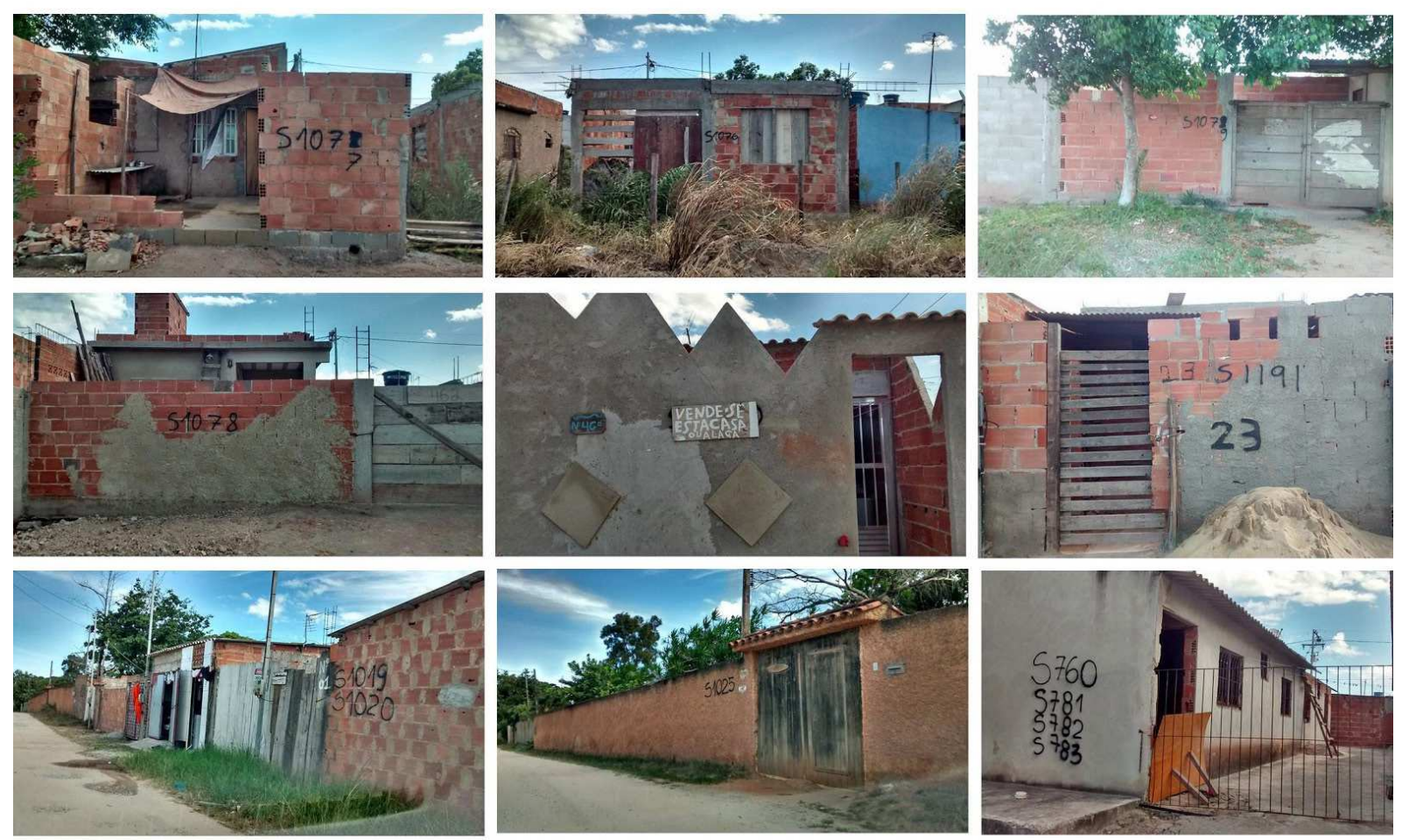

FIGURA 2 - Casas marcadas para fins de demolição. Legenda: Sequência de fotos. Casas marcadas para desapropriação por estarem localizadas em frente ao Parque Nacional da Restinga de Jurubatiba.

FONTE: fotos de Rafael Nogueira Costa.

${ }^{13}$ Ofício no 234/2015 - Coordenação Regional do Rio de Janeiro (CR8) - ICMBio. Assunto: TEPOR - Terminal Portuário de Macaé, RJ. Rio de Janeiro 08 de setembro de 2015. 
ausência de previsão de impactos à UC; ii) informações insuficientes sobre os Programas Ambientais propostos pelo empreendedor e iii) lacunas nos dados apresentados pelo empreendedor. A publicação do documento técnico e a participação de diversos atores - pesquisadores, pescadores, cidadãos, servidores do ICMBio e professores universitários - foram responsáveis por estabelecer uma reconfiguração territorial pautada na democracia e na qualidade ambiental (Martins et al., 2017).

Os fatos assinalaram "a existência de atores surpreendentes", modificando "por uma sucessão de acontecimentos imprevistos, a lista dos mediadores", agitando, perturbando, complicando, fazendo falar, tecendo e suscitando "uma viva controvérsia" (Latour, 2014, p. 181). Um exemplo foi a presença de "educadores ambientais" 14 atuando na faixa de gasoduto no Lagomar.

Como lembra Latour (2012), sempre que uma conexão for estabelecida, "um novo tubo condutor deve ser instalado e um novo tipo de entidade deve viajar por ele", e quando os lugares tornam-se alvos dessas atividades, ou seja, uma "encruzilhada" e "abrigo provisório de muitos desses veículos", transformando-se em atores numa complexa rede de associações (Latour, 2012, p. 316).

Criado pela área de engenharia da Petrobras em 2005, a iniciativa visava "manter as crianças longe das zonas de perigo dos gasodutos", oferecendo "atividades de recreação, usando brinquedos tradicionais, jogos e músicas infantis, competições, introduzindo as crianças ao mundo da literatura e noções de saúde, segurança e meio ambiente" (Pe- trobras, 2005, p. 35). Na visão da empresa, o principal objetivo do projeto é "garantir a integridade e o bem-estar da comunidade durante as obras de construção de empreendimentos da Petrobras" (Petrobras, 2015). O mesmo projeto é desenvolvido nos Municípios que recebem a instalação dos gasodutos da empresa, como em Caraguatatuba (SP), Angra dos Reis (RJ), Coari (AM) e Ipojuca (PE). Este tipo de ação está concentrada numa determinada etapa: dessa forma, a relação que se estabelece com os pequenos moradores é superficial e acaba quando os canos são enterrados. Algo parecido foi observado por Mia Couto em 1989 em Moçambique, quando uma equipe de técnicos das Nações Unidades desembarcou na Ilha da Inhaca:

\begin{abstract}
Não quero comentar aqui como esse conceito de educação ambiental esconde muitas vezes uma arrogância messiânica. A verdade é que, munidos de boa-fé, os cientistas traziam malas com projectores de slides e filmes. Traziam, enfim, aquilo que na sua linguagem designavam por "kits de educação", na ingénua esperança de que a tecnologia é a salvação para os problemas de entendimento e de comunicação (Couto, 2011, p. 16-17).
\end{abstract}

Por outro lado, existem inúmeras experiências bem sucedidas de conservação com base na participação da comunidade (Berkes, 2004). Para além do conflito e na sua esteira, o conhecimento sobre a realidade é produzido na associação de diferentes pontos de vista e interesses. É a percepção da indissociabilidade entre conflito e controvérsia, contexto e conceito, valores e fatos científicos que torna o

\footnotetext{
${ }^{14}$ Identificamos a atuação no Lagomar de profissionais, com formações acadêmicas e discursos variados, contratados pelas empresas de consultoria, prestadoras de serviços para as empresas do ramo petrolífero. Geralmente não são moradores das "áreas impactadas" e apresentam, aparentemente, pouco conhecimento sobre a realidade local, problema supostamente resolvido na fase do "diagnóstico socioambiental". Um novo mercado, surgido a partir dos licenciamentos ambientais.
} 
trabalho de campo descrito aqui importante para a formação dos participantes.

Na próxima seção, apresentaremos os relatos dos participantes do trabalho de campo, apontando como a produção de imagens pode contribuir para sua formação acadêmica, possibilitando, inclusive, novas formas de reflexão em relação ao locus da construção de saberes.

\section{Formação de professores-pesquisadores: compartilhando reflexões e olhares}

Para organizar a saída de campo, foram planejadas as seguintes etapas: i) delineamento da pesquisa, com ênfase para o estudo de caso; ii) obtenção de dados, concentrando em entrevista individual, observação sistemática, coleta de documentos e elaboração de filmes com estéticas diferenciadas; iii) análise de dados e edição do material audiovisual coletado em campo pelos grupos e iv) exibição dos filmes seguida de debate em grupo, gerando reflexões sobre a prática de campo como espaço para formação de professores-pesquisadores.

Visando proporcionar construções complementares, os discentes formaram quatro grupos, e cada um deles elaborou ${ }^{15}$ uma narrativa audiovisual distinta, conforme descrito por Nichols (2009) ${ }^{16}$ : modo expositivo (narrativa geralmente utilizada pelos telejornais); modo observativo (tem a intenção de interferir o mínimo possível durante as gravações); modo participativo (geralmente o documentarista é sujeito ativo no processo e interage de maneira mais clara); e modo poético (evidencia e enfatiza a subjetividade, com preocupação acurada com a estética, valorizando planos e impressões do universo registrado). Esta classificação não é sólida: geralmente existe uma interrelação nos fazeres, sendo que "um documentário reflexivo pode conter tomadas observativas" e participativas e "um documentário expositivo pode conter elementos poéticos" e performáticos (Nichols, 2009, p. 136).

As opções estéticas funcionam como alternativas metodológicas com técnicas de registro diferenciadas, não existindo um método que "possa garantir um acesso privilegiado ao real", e cada referência cinematográfica passa a ser "construída no interior do filme", funcionando como um "constructo" (Da-Rin, 2006, p. 221). Na montagem do filme - um dos objetivos do trabalho de campo - a construção ganha uma dimensão mais visceral e meditativa, uma vez que o filme "é montado a partir de muitas imagens e sequências de imagens, entre as quais o montador pode fazer a sua escolha" (Benjamin, 2012, p. 51), constituindo uma "noção de pedagogia baseada na montagem cinematográfica" (Migliorin $\&$ Barroso, 2016, p. 16). Após esta etapa foram exibidos os registros e compartilhados os olhares sobre o território estudado.

Diante das abordagens de cada grupo, pudemos notar que, por possuírem distinções e peculiaridades estéticas, elas acabaram se complementando

\footnotetext{
${ }^{15}$ Não foi objetivo do trabalho de campo divulgar o material produzido pelos discentes, pois envolveria questões éticas de uso de imagem e som de terceiros, o que poderia inviabilizar o trabalho de campo. Após a apresentação em grupo, o material audiovisual coletado foi apagado conforme acordado com os participantes.

${ }^{16}$ Nichols (2009) identifica seis modos, ou tipos, diferentes de documentário. Não foram experimentados produções com base nos tipos reflexivo e performático.
} 
e compondo um "mosaico de olhares" 17 sobre a realidade, conforme debatido pelos estudantes:

Houve uma ligação, um foi completando o outro. Porque eu também me identifiquei muito com a entrevista.

$\mathrm{Eu}$ gostei muito da poética, mas eu não consigo eleger uma (...) acho que tem que ser uma mistura, não consigo pensar em uma coisa só. É igual quando a gente pensa na escola, qual o modelo, qual a teoria que ela vai seguir? Ela vai ser tradicional, vai ser construtivista? Tem que mesclar.

Acho que um acabou completando o outro, pois ficamos com o modo observativo e acabou trazendo essas questões novas também, de que não há só um sentido, que as coisas não têm só um lado, existem vários fatores que influenciam na condição de uma realidade.

A proposta de produção audiovisual na formação de professores reforça os princípios da Educação Nacional preconizada pela Lei de Diretrizes e Bases da Educação (Brasil, 1996), definidos pelo artigo $3^{\circ}$ :

Liberdade de aprender, ensinar, pesquisar e divulgar a cultura, o pensamento, a arte e o saber; pluralismo de ideias e de concepções pedagógicas e valorização da experiência extraescolar (Art. $3^{\circ}$ da Lei 9.394 de 1996).

Uma das noções-chave que a atividade aqui descrita suscitou e que foi discutida com o grupo de participantes é a ausência da hierarquização de saberes assentada na visibilidade de formas de conhecimento para além da ciência moderna, co- mo os "conhecimentos populares, leigos, plebeus, camponeses ou indígenas" (Sousa Santos, 2010, p. 33). Em relação à percepção do diálogo e do saber ouvir, pontuou o estudante:

A princípio eu tinha a visão de que as casas desabaram porque não tinham estrutura. E depois que foi apresentada a visão da moradora [a partir de conversas informais], eu vi que não é isso. Então, o pensamento que recebemos em primeira instância, tomamos como verdade e depois vemos que não é, que não existe só uma verdade, nem só uma realidade.

É esse o caminho proposto por Paulo Freire, no qual o diálogo é a condição de existência humana. Por meio dele refletimos, agimos juntos no mundo que queremos transformar:

O diálogo é o encontro entre os homens, mediatizados pelo mundo, para designá-lo. Se, ao dizer suas palavras, ao chamar ao mundo, os homens o transformam, o diálogo impõe-se como o caminho pelo qual os homens encontram seu significado enquanto homens, o diálogo é, pois, uma necessidade existencial (Freire, 1980, p. 82).

No relato dos alunos, podemos identificar a importância do cinema como forma de compreensão de uma nova dimensão da realidade, permitindo o "reconhecimento da existência de uma pluralidade de formas de conhecimento", podendo funcionar como um modo para alcançar "a ecologia de saberes e a inesgotável diversidade da experiência do mundo" proposta por Sousa Santos (2010, p. 54).

\footnotetext{
${ }^{17}$ Como lembra Latour (2012), a sigla ANT, referente à proposta da actor network theory, está vinculada com a ideia do "pesquisador formiga". Desta forma, a partir dos olhos compostos das formigas, formamos um mosaico de olhares. Ou seja, somos nós as formigas percorrendo as fronteiras, observando a partir das lentes das câmeras e compondo uma paisagem em expansão.
} 
Este é o grande potencial do trabalho de campo realizado à luz da ecologia política, tal como definida por Latour. Especificamente quando ele nos indica que na construção deste campo, cientistas, políticos, militantes associam ação e produção de conhecimento sobre a realidade multiplicando os híbridos, que por sua vez agenciam outros atores.

A atividade de campo e a prática a ela associada dizem o que queremos ver transformado, que é a supremacia de algum tipo de saber sobre o outro. Assim, a adoção da postura epistemológica descrita neste artigo se relaciona à dimensão de ação na sociedade:

\begin{abstract}
Nós, como educadores, temos que nos preocupar quando estivermos atuando exatamente com essa questão que estamos vivenciando aqui: de levar os alunos pra ter contato com certa realidade. Muitas vezes dentro da sala de aula você passa o conteúdo teórico e não consegue trazer pro aluno a dimensão real daquilo. Quando você tem contato é outra visão, outro sentido, outra realidade. É muito especial esse momento. Vai fazer diferença pelo menos na minha vida como pessoa e educadora. Isso é, pra mim pelo menos, um crescimento enorme!
\end{abstract}

Este tipo de cinema está preocupado em desvendar as realidades problematizando a narrativa fílmica, pois "não é no silêncio que os homens se fazem, mas na palavra, no trabalho, na ação-reflexão" (Freire, 2013, p. 108). No ato de se reinventar e de narrar a sua verdade, de acordo com o seu ponto de vista. É na construção de "diálogos efetivos", que se constituem na troca de "informações com o objetivo de adquirir novas informações" (Flusser, 2007, p. 98). Dessa forma garantimos "uma produção de saber compartilhada" (Migliorin \& Barroso, 2016, p. 27). Sair da escola e se aproximar do cotidiano do aluno pode ampliar as abordagens educativas e reduzir a ingenuidade, como percebido:

Às vezes pode ser o nosso aluno que vive no Lagomar. É importante ter essa preocupação, também, de conhecer quem está ali, com quem você está trabalhando. Porque pode ter uma questão ambiental dentro de uma escola que você está trabalhando e você pode entrar e sair da sala sem nem saber o contexto que você está vivendo, de que realidade você está fazendo parte. Então, acho que traz isso também. (...) O cinema aproxima tudo isso desse universo do professor (grifo nosso).

A fala do estudante sintetiza o tipo de cinema que defendemos, que se "aproxima de tudo isso", que compõe o coletivo a partir da realidade, reinterpretando e criando diferentes modos de observar, se constituindo numa espécie de "matemática do olhar", de maneira a permitir experiências diferenciadas com os filmes (Marcello, 2013, p. 13). Para além da exibição de filmes nacionais em sala de aula, conforme determina a Lei Nacional $n^{\circ} 13.006$ (Brasil, 2014), é necessário promover reflexões sobre quem, como, onde, por que e para quem se produz o tipo de cinema que será integrado à proposta pedagógica da escola.

Neste sentido, o que estamos chamando de $\mathrm{Ci}$ nema Ambiental Freiriano seria a práxis do pensar e fazer cinema, partindo de uma perspectiva ampliada de ambiente que emerge do território. Como metodologia para se pensar a construção da narrativa, Paulo Freire nos presenteia com a "investigação dos temas geradores". Os temas geradores e os registros que surgem da experiência dialógica possibilitam a exteriorização de visões de mundo, "a forma de pensá-lo" e compreender uma "situação limite" (Freire, 2013, p. 133-136). 
A complexidade do tema, as suas múltiplas formas de observar o território e de lhe dar significados na busca por alternativas foram reflexões de um participante:

O petróleo também é importante, é progresso, tem um sentido (...) não dá pra coexistir de uma forma que seja boa pra todos? Tem a restinga, tem o parque, tem o gasoduto que também é importante, a gente vai chegar a uma solução? Acho que minha questão foi essa: Como a gente vai chegar em algum lugar? Porque ali está tudo assim: as pessoas de um lado, o gasoduto, o Parque, e aí?

Apesar das dúvidas do estudante, ficou claro no debate em grupo que o conceito de sustentabilidade $^{18}$, embora bastante controverso, não se aplica para a atividade petrolífera. Pois esta atividade encontra-se calcada num recurso finito e limitada a um pequeno número de companhias (Juhasz, 2009). Entre todas as fontes de energia, o petróleo "vem se mostrando a maior e mais problemática devido ao seu papel central", gerando guerras e disputas, "acusada de ser uma ameaça para a geração presente e as futuras" e ampliando as alterações climáticas globais (Yergin, 2012, p. 15-886). Portanto, insustentável.

Quanto ao processo de aprendizagem vivenciado pelos estudantes, destacamos a importância do trabalho de campo na formação dos futuros educadores, pois geralmente a sala de aula tradicional é vertical, proporcionando pouco debate e reflexão e, na maioria das vezes, mostra apenas a existência de uma única realidade. Os futuros professores poderão escolher entre adotar em sua prática escolar uma conduta de superioridade frente aos demais tipos de conhecimento ou repensá-la, experimentando outro ponto de vista sobre a construção do conhecimento e compreendendo o quanto a adoção deste ponto de vista epistemológico é política.

\section{Considerações finais}

Esse trabalho parte da ideia de que é possível criar espaços de formação para educadores-pesquisadores apoiados em atividades de campo e na produção coletiva de filmes. A pesquisa com os estudantes do Curso de Pedagogia revelou que a mesma natureza - o Parque Nacional da Restinga de Jurubatiba - apresenta ontologias variadas, mas compondo um mundo comum a todos. A criação compartilhada de produtos audiovisuais contribui na formação acadêmica, a partir do momento em que as verdades são postas de lado e as ações e a própria natureza são multiplicadas. Olhar a realidade de maneira ampliada, conforme aponta a teoria ator-rede, possibilita a compreensão de continuidade e das conexões entre atores que provavelmente não entrariam no curso da história, como o gasoduto, o terminal e a refinaria de petróleo, a câmera, a formiga, entre outros.

Podemos afirmar que o produto desta experiência, para além dos filmes, estimulou um debate entre os estudantes sobre noções-chave que direcionam a construção do conhecimento sobre uma realidade particular, dentre as quais está o conceito de que a pesquisa se faz "com" e não "sobre" os outros, que está presente naquilo que Latour (2004) defende como sendo "fazer ecologia política".

\footnotetext{
${ }^{18}$ Compreendido de maneira complexa e interdependente em seis princípios: socialmente justo, economicamente viável, politicamente ético, culturalmente aceito, ambientalmente ecológico, geracionalmente inclusivo, conforme descrito por Silva \& Mendes (2005).
} 
Promover a "cultura da expressão" é um caminho oposto ao da "cultura do silêncio". Conhecer as realidades dos moradores do antigo lixão da "Capital do Petróleo", dos moradores do manguezal ou do bairro mais próximo a um terminal de petróleo é proporcionar a multiplicação de mundos. Mostrá-los, em forma cinematográfica, real, visceral, orgânica, é promover reflexões, relatos políticos, discursos que entram no curso da ação, podendo até transformar a realidade na medida em que as pessoas se percebem como construtoras das suas próprias realidades.

\section{Agradecimentos}

Aos moradores da Rua W-30 (Avenida MPM) do Lagomar, pela luta diária por um tratamento mais humano e digno. Aos discentes do curso de Licenciatura em Pedagogia da UERJ. Este manuscrito é mais uma das muitas provas de que a UERJ resiste.

À Fernanda Antunes Gomes (Professora de Literaturas Africanas e Linguagens na UFRJ Macaé), pelas dicas. À Astréa Castro (técnica em audiovisual na UFRJ Macaé), pela revisão. Aos participantes dos Coletivo de Pesquisa em Cinema Ambiental (CUCA/UFRJ), pelas trocas durante os encontros formativos.

\section{Referências}

Almeida, R. Cinema e Educação: Fundamentos e perspectivas. Educação em Revista, 33, 1-27, 2017. doi: 10.1590/0102-4698153836

Beck, U. Sociedade de Risco: Rumo a uma outra modernidade. São Paulo: Editora 34, 2011.

Benjamin, W. A obra de arte na época de sua reprodutibi- lidade técnica. Porto Alegre, RS: Zouk, 2012.

Berkes, F. Rethinking Community-Based Conservation. Conservation Biology, 18, 3, 621-630, 2004. doi: 10.1111/j. 1523-1739.2004.00077.x

Bosco, E.; Di Giulio, G. M. Ulrich Beck: considerações sobre sua contribuição para os estudos em Ambiente e Sociedade e desafios. Ambiente \& Sociedade, 18(2), 145156, 2015.

Brasil. Lei $n^{\circ}$ 6.938, de 31 de agosto de 1981. Dispõe sobre a Política Nacional do Meio Ambiente, seus fins e mecanismos de formulação e aplicação, e dá outras providências. Brasília: DOU de 02/09/1981.

Brasil. Lei $n^{\circ}$ 9.394, de 20 de dezembro de 1996. Estabelece as diretrizes e bases da educação nacional. Brasília: DOU de 23/12/1996.

Brasil. Sistema Nacional de Unidades de Conservação da Natureza - SNUC, 2000. Disponível em: <http://www. planalto.gov.br/ccivil_03/leis/19985.htm>

Brasil. Lei $n^{\circ}$ 13.006, de 26 de junho de 2014. Obriga a exibição de filmes de produção nacional nas escolas de educação básica. Brasília: DOU de 27/06/2014.

Cordeiro, M. R.; Rodrigues, S. M.; Souza, P. R. N.; Ferreira, M. I. P. Gestão de Efluentes Domésticos. Fossa Séptica. Contaminação de Águas Subterrâneas. Restinga de Jurubatiba. Boletim do Observatório Ambiental Alberto Ribeiro Lamego, 5, 89-102, 2012. doi: 10.19180/2177-4560.20110005

Correa, R. M. Diagnóstico e plano municipal de prevenção à violência e criminalidade do município de Macaé. $1^{\mathrm{a}} \mathrm{ed}$. Prática e Saberes, 3. Rio de Janeiro: Viva Rio, 2012.

Costa, R. N.; Branquinho, F. T. B. A fronteira entre a comunidade e a Unidade de Conservação mastigada pela formiga-onça. Iluminuras, 17, 42, 527-542, 2016. doi: 10.22456/1984-1191.70011

Costa, R. N.; Machado, C. J. S.; Branquinho, F. T. B. Produção audiovisual no contexto da educação ambiental exigida no licenciamento de petróleo e gás no Estado do Rio de Janeiro. Desenvolvimento e Meio Ambiente, 36, 273-290, 2016. doi: 10.5380/dma.v36i0.43014

Couto, M. E se Obama fosse africano?: e outras interin- 
venções. $1^{a}$ ed. São Paulo: Companhia das Letras, 2011.

Cuzzati, T. G.; Marques, E. D.; Tubbs, D. Avaliação preliminar da vulnerabilidade na unidade Aquífera do Bairro Lagomar, Macaé-RJ. In: Anais: XII Congresso Brasileiro de Geoquímica. Gramado-RS, 2011.

Da-Rin, S. Espelho Partido. Rio de Janeiro: Azougue Editorial, 2006.

Dias, R. Instituições e desenvolvimento territorial: um estudo a partir do caso do arranjo produtivo de petróleo e gás natural localizado em Macaé-Brasil. EURE (Santiago), 39, 116, 141-171, 2013. doi: 10.4067/S025071612013000100006

Faria, T. P.; Tougeiro, J. V. Conflitos socioambientais motivados por ocupação de manguezais e restingas para fins habitacionais no espaço urbano de Macaé, RJ. Revista Internacional Interdisciplinar INTERthesis, 7, 1, 242-271, 2010. doi: 10.5007/1807-1384.2010v7n1p242

Flusser, V. O mundo codificado: por uma filosofia do design e da comunicação. São Paulo: Cosac Naify, 2007.

Freire, P. Conscientização: teoria e prática da libertação - uma introdução pensamento de Paulo Freire. $4^{a}$ Ed. São Paulo: Moraes, 1980.

Freire, P. Pedagogia da autonomia: saberes necessários à prática educativa. São Paulo: Paz e Terra, 1996.

Freire, P. Pedagogia do oprimido. 54 $4^{\mathrm{a}}$ Edição. Rio de Janeiro: Paz e Terra, 2013.

Fuentes, N. M. M.; Costa, R. N.; Ruta, C. Cinema e Educação Ambiental no Parque Nacional da Restinga de Jurubatiba: Reflexões e práticas interdisciplinares e transversais. Educação e sociedade, 37, 136, 893-911, 2016. doi: 10.1590/es0101-73302016160464.

Goldfarb, B. Visual Pedagogy: Media Cultures in and beyond the Classroom. Durham, NC: Duke University Press, 2002.

Juhasz, A. A tirania do petróleo: a mais poderosa indústria do mundo e o que pode ser feito para detê-la. São Paulo: Ediouro, 2009.

Lamego, A. R. O homem e o brejo. Rio de Janeiro: IBGE. 1945.
Latour, B. Políticas da natureza. Como fazer ciência na democracia. Trad. de Carlos Aurélio Mota de Souza. Bauru, SP: Edusc, 2004.

Latour, B. Reagregando o social: Uma introdução à teoria ator-rede. Salvador: Edufba, 2012.

Latour, B. Para distinguir amigos e inimigos no tempo do Antropoceno. Revista de Antropologia, 57, 1, 11-31, 2014. doi: 10.11606/2179-0892.ra.2014.87702

Leal, G. F. Justiça ambiental, conflitos latentes e externalizados: estudo de caso de pescadores artesanais do norte fluminense. Ambiente \& Sociedade, 16, 4, 83-99, 2013. doi: 10.1590/S1414-753X2013000400006

Macaé. Plano Local de Habitação de Interesse Social. Diagnóstico das Necessidades Habitacionais e Estratégias de Ação. Macaé (RJ), 2010.

Macaé. Anuário de Macaé 2012. Coordenadoria Geral do Programa Macaé Cidadão. Prefeitura Municipal de Macaé, 2012.

Machado, A. A. O local e o global na estrutura da política ambiental internacional: a construção social do acidente químico ampliado de Bhopal e da Convenção 174 da OIT. Contexto internacional, 28, 1, 7-51, 2006. doi: 10.1590/ S0102-85292006000100007

Madeira Filho, W.; Roriz, J. E.; Silveira, A. C. Poluição cívica: criminalização do Bairro Lagomar no Município de Macaé e ajustamentos de conduta. In: Herculano, S. Oficina sobre impactos sociais, ambientais e urbanos das atividades petroliferas: o caso de Macaé (RJ). $1^{\mathrm{a}}$ ed. Niterói: PPGSD-UFF, 1, 2011.

Marcello, F. A. Seleção, soma, multiplicação: matemáticas do olhar no trabalho com cinema e educação. In: Guimarães, L. B.; Guido, L. E. (Orgs.). Cinema, Educação e ambiente. Uberlândia, EDUFU, 13-23, 2013.

Martins, R. L.; Camargo, G. A.; Leal, G. F. Espaço para a extensão universitária no campo socioambiental: um estudo de caso sobre as audiências públicas do Terminal Portuário de Macaé. In: Leal, E. M.; Escudero, R. (Orgs.). Problemas globais, enfrentamentos locais e a universidade pública. Universidade Federal do Rio de Janeiro, Campus Macaé, RJ: 2017. 
Medeiros, R.; Pereira, G. S. Evolução e implementação dos planos de manejo em parques nacionais no estado do Rio de Janeiro. Árvore, 35, 2, 279-288, 2011. doi: 10.1590/ S0100-67622011000200012

Migliorin, C.; Barroso, E. I. Pedagogias do cinema: montagem. Significação, 43(46), 2016. doi: 10.11606/issn.23167114.sig.2016.115323

Nichols, B. Introdução ao documentário. Campinas: Papirus, 2009.

Petrobras. Social and environmental report. Petrobras and United Nations Global Compact, Petrobras, 2005. Disponível em: http://bit.ly/1qmK2S6

Petrobras. Informativo do Complexo Petroquímico do Rio de Janeiro, Comperj. № 52 - Ano V, 2015.

Santos, M. C. Contribuição à gestão das lagoas costeiras: conhecimento tradicional, técnico e científico associado ao manejo dos recursos naturais da Lagoa de Carapebus, Parque Nacional da Restinga de Jurubatiba - RJ. Dissertação de Mestrado. Programa de Pós-graduação em Engenharia Ambiental. Instituto Federal Fluminense. Macaé. 2008. 135 p.

Silva, S. R. A.; Faria, T. J. P. Migration in Macae: Impacts of Industrialization in the Urbanization Process. Vértices, 14, 2, 111-132, 2012.

Silva, C. L.; Mendes, J. T. G (Orgs.). Reflexões sobre o Desenvolvimento Sustentável. Agentes e interações sob a ótica multidisciplinar. Petrópolis: Vozes, 2005.

Sodré, M. Reinventando a educação: diversidade, descolonização e redes. $2^{\mathrm{a}}$ ed. Petrópolis, RJ: Vozes, 2012.

Souza Santos, B. Para além do pensamento abissal: das linhas globais a uma ecologia de saberes. In: Souza Santos, B.; Meneses, M. P. Epistemologias do sul. São Paulo: Cortez, 2010.

Souza, S. J. O pesquisador-cineasta e a ética dos olhares compartilhados. Revista de Psicologia, 8, 1, 2017. Disponível em: http://www.repositorio.ufc.br/handle/riufc/27936

Yergin, D. O petróleo: uma história mundial de conquistas, poder e dinheiro. Rio de Janeiro: Paz e Terra. 2012.

Vainer, A. G. Ordenamento Territorial e Conflitos no Parque Nacional da Restinga de Jurubatiba. Anais: V Encontro
Nacional da Anppas. Florianópolis, SC. 2010.

\section{Filmografia}

Um dia novinho em folha. Rafael Nogueira Costa e Rafael Quintas Alves. CUCA/UFRJ. 2013. $22 \mathrm{~min}$.

Espelho d'água: Bailarina do Lagomar. Liz Vitt e Rafael Nogueira Costa. CUCA/UFRJ. 2015. 19 min.

Cicatrizes numéricas. Produção coletiva do CUCA/UFRJ. 2017. $4 \mathrm{mim}$.

Vento corredor. Humanomar, Projeto de Educação Ambiental exigido pelo IBAMA. 2007. $16 \mathrm{mim}$. 